\title{
Toxic trace elements in selected edible rhizomes of medicinal plants using INAA and ICP-MS techniques
}

\begin{abstract}
Consumption the crop is one of the main sources of dietary exposure to toxic trace elements. In order to assess the level of toxic trace elements from selected herbs and to make an assumption on their consumption level of concern, fourteen elements in Zingiber zerumbet(lempoyang), Boesenbergia rotunda (temu kunci), Zingiber officinale var rubrum (halia bara) and Zingiber officinale roscoe (halia) have been determined via ICP-MS (Cd, $\mathrm{Be}, \mathrm{Ti}, \mathrm{Pb}$ ) and INAA (As, $\mathrm{Al}, \mathrm{Ba}, \mathrm{Cr}, \mathrm{Co}, \mathrm{Sb}, \mathrm{Sr}, \mathrm{Th}, \mathrm{U}$ and $\mathrm{V}$ ) methods. It was revealed that the concentrations of these elements in most selected rhizomes did not exceed the standard dangerous toxic level. However, 47\% cadmium accumulationa was detected in Zingiber officinale var rubrum grown in poly-bags.
\end{abstract}

Keywords: toxic element, herbs, rhizomes, inaa, icp-ms
Volume 6 Issue 4 - 2017

\author{
AbuBakar Mohd Daran,' Kamaludin Rashid, ${ }^{2}$ \\ Halijah Ibrahim, ${ }^{3}$ Mahanom Jalil, ${ }^{2}$ Yusmin \\ Mohd Yusof, ${ }^{2}$ Shamrulazhar Shamzir Kamal, ${ }^{3}$ \\ Shahril Efzueni, ${ }^{2}$ Reza Farzinebrahimi ${ }^{2}$ \\ 'Department of Physics, University of Malaya, 50603 Kuala \\ Lumpur, Malaysia \\ ${ }^{2}$ Department of Biology, University of Malaya, Malaysia \\ ${ }^{3}$ Institute of Biological Sciences, University of Malaya, Malaysia
}

Correspondence: Reza Farzinebrahimi, Institute of Biological Sciences, Faculty of Science Building, University of Malaya, 50603 Kuala Lumpur, Malaysia, Tel 0060173030586.

Email rfebrahimi@siswa.um.edu.my

Received: October 29, 2016 | Published: April 21, 2017
Abbreviations: Cd, cadmium; Be, beryllium; Ti, thallium; $\mathrm{Pb}$, lead; As, arsenic; $\mathrm{Al}$, aluminum; $\mathrm{Ba}$, barium; $\mathrm{Cr}$, chromium; $\mathrm{Co}$, cobalt; $\mathrm{Sb}$, antimony; $\mathrm{Sr}$, strontium; Th, thorium; $\mathrm{U}$, uranium; $\mathrm{V}$, vanadium; MRL, minimal risk level; INAA, instrumental neutron activation analysis; ICP-MS, inductively coupled plasma/mass spectrometry

\section{Introduction}

The interaction between chemical extracted compounds from plants and the human body go through the same identical process to those well understood for the chemical compounds in conventional drugs. Similarly, the herbal medicine may cause the same potential to cause a side effect. ${ }^{1}$ Zingiber zerumbet(lempoyang), Boesenbergia rotunda (temu kunci), Zingiber officinale var. rubrum (halia bara) and Zingiber officinale roscoe are belonging to Zingiberaceae or Ginger family consisting of aromatic perennial herbs with creeping horizontal or tuberous rhizomes planted locally. The same species can be found throughout tropical Africa, Asia, and the America. These rhizomes are a common edible ingredient in many countries, in South East Asia and serve as culinary herbs due to their aromatic flavor to promote appetite.

Their popularities as folk medicine have drawn further interest amongst researchers to investigate on various perspectives about their medicinal properties. Eng-Chong et al., ${ }^{2}$ Sivasothy et al., ${ }^{3} \&$ Sontakke et al., ${ }^{4}$ have been reported on medicinal crop areas. A list of possible treatments for illnesses using the described rhizomes is shown in Table 1.

Trace elements may take by medicinal plants from the surrounding mineral or contaminated soil environment via the root system and translocation within at various part of the plant such as in the rhizome, stems, and leaves. Some plants can absorb trace elements from the soil in high quantity and do not present toxicity symptoms or have their growth affected. These plants are suitable for remediation of polluted soils known as Phytoremediation. ${ }^{5}$ Accumulation of toxic trace element above minimal risk level (MRL) value or provisional tolerable index level, ingested by humans for a long term, will give an adverse effect to human health depending on the type of trace elements present.

The present study was undertaken to determine the level of toxic trace elements found in the rhizome samples and to make an assumption on their consumption level of concern if ingested by an adult based on the MRL tabulated by the Agency for Toxic Substances and Disease Registry. ${ }^{6}$

\section{Materials and method}

The rhizomes of four species, namely $Z$. zerumbet (A), B. rotunda $(\mathrm{B}, \mathrm{C}), Z$. officinale var. rubrum $(\mathrm{D}, \mathrm{E})$ and $Z$. officinale Roscoe (F) were collected from the surrounding area in the University of Malaya. The B.rotunda was separated into a center piece or the top part and the tubular shape and Z. officinale var. rubrum were taken from the wild and planted in polybag condition.

The samples were pre-rinsed with deionized water and dried at $39^{\circ} \mathrm{C}$ in the oven for five hours. The dried samples were powdered using mortar and pestle to make a dried rhizome powder. The powders were sieved using a standard set of sieves. About 15-100g of grounded sample was weighed and sealed in the polyethylene vials and tagged as A, B, C, D, E and F according to the species and their origin. A duplicate was used up for each analyte sample and blank for error correction.

Standard coal ash SRM-1632a based on (NIST) ${ }^{7}$ was employed as a multi element comparison standard. The Analyte and standard samples were stacked up in a rotary rack at different positions ready for irradiation.

\section{Irradiation and counting}

The irradiation facility was carried out by TRIGA MK II (Malaysian Institute of Nuclear Technology, MINT) for 6hours at a thermal flux $(2 \times 1012 \mathrm{ncm}-2 \mathrm{Sec}-1)$. After irradiation, the vial is returned from the reactor by atmospheric pressure and allowed to decay to the level of activity is within acceptable limits for handling. Cooling time was arranged according to the nuclear properties of 
radioisotopes. Medium-lived species were counted after four days of cooling while a decay time of nearly a month was set aside for a longlived isotope. Each sample was placed in the appropriate position on the detector for counting.

For the gamma spectra measurement, a solid state horizontal hyper pure germanium (HPGe) detector was used. A nuclear Data 66 multichannel analyzer was used for pulse height analysis. The gamma spectra analyses were carried out by using the software Genie 2000 and gamma vision supplied by ORTEC and Canberra, respectively.
Heavy metals and non-measurable by Instrumental Neutron Activation Analysis (INAA), such as $\mathrm{Pb}, \mathrm{Be}, \mathrm{Tl}$, and $\mathrm{Cd}$ were analyzed using a Perkin-Elmer SCIEX Elan 6000 Inductively Coupled Plasma/ Mass Spectrometry (ICP-MS).

The dry duplicate sample was weighed $(0.5 \mathrm{~g})$ and transferred into a beaker $(10 \mathrm{~mL})$ followed by concentrated $\mathrm{HNO}_{3}(5 \mathrm{~mL})$. The sample was pre-digested for one hour, and the beaker was heated up on a hot plate at $60-70^{\circ} \mathrm{C}$.

Table I Medicinal plants and its uses

\begin{tabular}{|c|c|c|}
\hline Species & Parts used & Treatment of \\
\hline \multirow{2}{*}{ Boesenbergia rotunda } & Swollen roots and leaves & $\begin{array}{l}\text { Rheumatism, pain killer, gout, gastrointestinal } \\
\text { disorders, stomach ache, dyspepsia and peptic } \\
\text { ulcer }^{2}\end{array}$ \\
\hline & Rhizome & $\begin{array}{l}\text { Anti cancer }{ }^{12} \\
\text { wound healing }\end{array}$ \\
\hline Zingiber zerumbet & Rhizome & $\begin{array}{l}\text { Inflammation and pain-mediated diseases, worm } \\
\text { infestation and diarrhea }{ }^{3} \\
\text { Anti cancer }\end{array}$ \\
\hline Zingiber officinale var. rubrum & Rhizome & Anti cancer, nausea, antibacterial activity ${ }^{14}$ \\
\hline Zingiber officinale Roscoe & Rhizome & Nausea (seasickness), morning sickness and ${ }^{4,15}$ \\
\hline
\end{tabular}

Table 2 Result for samples analyzed using ICP-MS and INAA techniques

\begin{tabular}{|c|c|c|c|c|c|c|c|}
\hline & \multirow{2}{*}{ Elements } & \multicolumn{6}{|c|}{ Concentration (ppm) } \\
\hline & & A & B & C & $\mathrm{D}$ & $\mathrm{E}$ & $\mathrm{F}$ \\
\hline & $\mathrm{Cd}$ & $0.02 \pm 0.01$ & $0.04 \pm 0.02$ & $0.04 \pm 0.01$ & $0.44 \pm 0.01$ & $0.10 \pm 0.01$ & $0.22 \pm 0.01$ \\
\hline ICP-MS & $\mathrm{Be}$ & $<0.01$ & $<0.01$ & $<0.01$ & $<0.01$ & $0.02 \pm 0.01$ & $<0.01$ \\
\hline \multirow[t]{6}{*}{ method } & $\mathrm{TI}$ & $<0.01$ & $0.02 \pm 0.01$ & $<0.01$ & $0.07 \pm 0.01$ & $0.02 \pm 0.01$ & $<0.01$ \\
\hline & $\mathrm{Pb}$ & $1.04 \pm 0.10$ & $1.45 \pm 0.07$ & $0.66 \pm 0.07$ & $0.62 \pm 0.20$ & $2.29 \pm 0.11$ & $1.07 \pm 0.12$ \\
\hline & As & $0.09 \pm 0.01$ & $0.07 \pm 0.01$ & $0.13 \pm 0.01$ & $0.40 \pm 0.02$ & $<0.05$ & $0.05 \pm 0.01$ \\
\hline & $\mathrm{Al}$ & $254 \pm 40$ & $242 \pm 35$ & $213 \pm 54$ & $<1.0$ & $<1.0$ & $<1.0$ \\
\hline & $\mathrm{Ba}$ & $<1.0$ & $23.7 \pm 0.7$ & $8.74 \pm 2.01$ & $14.7 \pm 1.6$ & $10.1 \pm 1.9$ & $4.05 \pm 0.81$ \\
\hline & $\mathrm{Cr}$ & $1.52 \pm 0.94$ & $1.55 \pm 0.21$ & $3.44 \pm 0.28$ & $3.84 \pm 0.43$ & $0.54 \pm 0.09$ & $0.38 \pm 0.08$ \\
\hline INAA & Co & $0.6 I \pm 0.05$ & $0.23 \pm 0.01$ & $0.20 \pm 0.01$ & $0.27 \pm 0.01$ & $0.36 \pm 0.01$ & $<0.1$ \\
\hline \multirow[t]{5}{*}{ method } & $\mathrm{Sb}$ & $<0.05$ & $<0.05$ & $<0.05$ & $<0.05$ & $<0.05$ & $<0.05$ \\
\hline & $\mathrm{Sr}$ & $<1.0$ & $<1.0$ & $<1.0$ & $<1.0$ & $10.1 \pm 1.0$ & $9.3 \pm 1.0$ \\
\hline & Th & $0.26 \pm 0.01$ & $0.99 \pm 0.19$ & $1.21 \pm 0.07$ & $0.55 \pm 0.02$ & $0.62 \pm 0.08$ & $1.03 \pm 0.03$ \\
\hline & $U$ & $<0.05$ & $0.09 \pm 0.02$ & $0.1 I \pm 0.01$ & $0.05 \pm 0.02$ & $<0.05$ & $<0.05$ \\
\hline & $\mathrm{V}$ & $<0.1$ & $<0.1$ & $<0.1$ & $<0.1$ & $<0.1$ & $<0.1$ \\
\hline
\end{tabular}

Table 3 Estimation of tolerable dietary intake of rhizomes

\begin{tabular}{|c|c|c|c|c|}
\hline \multirow{2}{*}{ Elements } & ATSDR (MRL)a & @ 60 Kg BW & WHO (1999)b & Consumption Level of Concern \\
\hline & ppm BW/day & mg/day & ppm & g/day (sample) \\
\hline $\mathrm{Cd}$ & 0.0005 (Int.) & 0.03 & 0.3 & $68(\mathrm{D})$ \\
\hline $\mathrm{Be}$ & 0.002 (Chr.) & 0.12 & & $6000(\mathrm{E})$ \\
\hline $\mathrm{TI}$ & 0.002 & 0.12 & & $17 \mid 4(D)$ \\
\hline $\mathrm{Pb}$ & $0.007 c$ & 0.42 & 10 & $183(\mathrm{E})$ \\
\hline As & 0.005 (Acute) & 0.3 & I & $750(\mathrm{C})$ \\
\hline $\mathrm{Al}$ & I (Int.) & 60 & & $236(\mathrm{~A})$ \\
\hline $\mathrm{Ba}$ & 0.2 (Int.) & 12 & & $506(B)$ \\
\hline $\mathrm{Cr}$ & 0.005 (Int.) & 0.3 & & 78 (D) \\
\hline Co & 0.0 I Int.) & 0.6 & & $983(\mathrm{~A})$ \\
\hline Sb & 0.0004( & 0.024 & & 480() \\
\hline $\mathrm{Sr}$ & 2 (Int.) & 120 & & $1200(E)$ \\
\hline Th & 15 pCi/Ld & 0.13 & & $109(\mathrm{C})$ \\
\hline$U$ & 0.002 (Acute) & 0.12 & & $1090(\mathrm{C})$ \\
\hline V & 0.01 (Int.) & 0.6 & & 6000() \\
\hline
\end{tabular}

A $2 \mathrm{~mL}$ of $\mathrm{HNO}_{3}$ and $3 \mathrm{~mL}$ of $\mathrm{HClO}_{4}$ were dropped slowly until the solution becomes clear and dissolved. The solution was filtered out using filter paper then was added up with deionized water $(30 \mathrm{~mL})$. The blank was prepared using the same reagents undergoing the similar digestion procedure. If necessary, the sample and blank were diluted accordingly prior analysis. Moreover, enough samples based on IAEA-SOIL-7 were digested with some digestion groups to assure the accuracy of the analytical procedures.

The elemental compositions for the four selected rhizome species, determined by ICP-MS and INAA are shown in Table 2. The samples are labeled as A, B, C, D, E and F with all concentrations are expressed 
in parts per million (ppm). A total of 14 elements was detected. The $\mathrm{Cd}, \mathrm{Be}, \mathrm{Tl}$ and $\mathrm{Pb}$ by ICP-MS, and $\mathrm{As}, \mathrm{Al}, \mathrm{Ba}, \mathrm{Cr}, \mathrm{Co}, \mathrm{Sb}, \mathrm{Sr}, \mathrm{Th}, \mathrm{U}$ and $\mathrm{V}$ were revealed by INAA technique.

A, Z.zerumbet (lempoyang); B, B.rotunda (temu kunci)- centre piece; C, Boesenbergia rotunda (temu kunci)- tubular shape; D, Z.officinale var rubrum (halia bara) - polybag environment; E, Z.officinale var rubrum (halia bara)- wild environment; F, Z.officinale Roscoe (halia)

\section{Result and discussion}

The high concentration of aluminum ( $>200 \mathrm{ppm})$ was observed in $Z$. zerumbet and $B$. rotunda in center piece and tubular shape. However, the trace amount was recorded in $Z$. officinale var rubrum (polybag and wild environment) and $\mathrm{Al}$ ions in $Z$. officinale Roscoe translucent very slowly to the upper parts of plants. ${ }^{8}$ The distribution of toxic trace elements in the studied rhizomes showed that the $\mathrm{Al}$ and $\mathrm{Ba}$ are found to be present at the major level, $\mathrm{Cr}, \mathrm{Pb}$, and $\mathrm{Tl}$ at the minor level and $\mathrm{Cd}, \mathrm{Co}, \mathrm{Sb}, \mathrm{Sr}, \mathrm{Th}, \mathrm{U}$ and $\mathrm{V}$ at the trace level. Most plants contain no more than $0.2 \mathrm{mg} \mathrm{Al}$ g-1 dry mass, and this caused that the rhizomes of sample $\mathrm{A}, \mathrm{B}$ and $\mathrm{C}$ is not an $\mathrm{Al}$ accumulator.

B. rotundasp. (samples B and C) was accumulated with a higher mean of $\mathrm{Ba}$ concentration compared to Z.officinale var rubrum sp. (samples D and E). A little amount was detected from $Z$. zerumbet (sample A). Sample D was recorded rich of Cd, Tl, As, Ba and $\mathrm{Cr}$ compare to other specimens. Even compared to the sibling sample E, the ratio of these toxic minerals can go from 1.5-8 folds higher. In a contrary, sample $\mathrm{E}$ absorbed more $\mathrm{Pb}$ and $\mathrm{Sr}$. Since sample D and $\mathrm{E}$ grew in different cultures thus the sources of toxic elements up taken by the plants may come from the soil compost, the fertilizer or the polybag. Heavy metals are often used in pigments or as stabilizers in polymer materials. Thus, polymers inevitably contain hazardous metals or toxic elements such as $\mathrm{As}, \mathrm{Cd}, \mathrm{Cr}$ and $\mathrm{Zn}$ to a certain degree. ${ }^{9}$

Similarly, sample $\mathrm{B}$ showed higher concentrations of $\mathrm{Pb}$ and $\mathrm{Ba}$ over sample $\mathrm{C}$ that in contrary marks higher concentration in $\mathrm{Cr}$. It led to $\mathrm{Pb}$ and $\mathrm{Ba}$ translocated at the centerpiece of the rhizome while $\mathrm{Cr}$ resides more in the tuberous shape. Other elements observed a balanced distribution throughout the rhizome of B.rotunda sp. The $\mathrm{Sr}$ was only detected in sample $\mathrm{E}$ and $\mathrm{F}$. Concentration of $\mathrm{Be}, \mathrm{Sb}$ and $\mathrm{V}$ were below the detection level (undetected) for all samples. Comparatively, sample A, B and $\mathrm{C}$ contain a high amount of toxic trace mineral observed, whereas sample $\mathrm{D}, \mathrm{E}$ and $\mathrm{F}$ are due to the negligible contribution from Al.

The estimation of tolerable dietary intake of the selected rhizomes was calculated based on the published data from. ${ }^{6,10}$ According to the guideline for the medicinal plant, ${ }^{10}$ the concentrations of $\mathrm{As}, \mathrm{Cd}$ and $\mathrm{Pb}$ do not exceed the limits of $1,0.3$ and $10 \mathrm{ppm}$ respectively. Based on Table 3, the concentration of $\mathrm{As}, \mathrm{Cd}$ and $\mathrm{Pb}$ were measured below the recommended limit except in sample D where it registered $47 \%$ higher for Cd. For Duration, Acute $=1$ to 14days, Intermediate $=15$ to 364 days, and Chronic $=1$ year or longer. a6, b10, c16, d17.

The minimal risk level (MRL) tabulated by ATSDR was used to estimate the number of rhizomes may be consumed per day. For example, the MRL of Cd taken orally continuously for 15 days to a year without giving adverse health effect is $0.0005 \mathrm{ppm} \mathrm{BW/day.}$ Assuming an adult of $60 \mathrm{~kg} \mathrm{BW}$ may require $0.03 \mathrm{mg}$ of the $\mathrm{Cd} /$ day for biosystem sustainability function. The consumption level of concern for $\mathrm{Cd}$ was calculated from the ratio of adult MRL to the maximum value in Cd column detected from the samples. As shown in Table 2 , sample $\mathrm{D}$ was recorded the highest concentration of $\mathrm{Cd}$, and the tolerable dietary intake of rhizome D was only $68 \mathrm{~g}$. Similarly, the MRL for Cr was attained when someone ingested a dry weight of $78 \mathrm{~g}$ of the same rhizome.

An herbal infusion of these rhizomes may dilute the concentration of toxic trace element to some extent due to low extraction efficiency and in some cases the inorganic toxic trace element such as were not detected in water infusion. ${ }^{11}$

\section{Conclusion}

The obtained amount of toxic trace elements in medicinal rhizomes is being less than the permissible levels allowed by the MRL standard of ATSDR. Cadmium, Tellurium, Arsenic, and Chromium showed high concentration in $Z$. officinalevar rubrum (growth in polybag environment). However, the level of Cadmium detected higher than the recommended level. In Z. officinalevar rubrum (growth in the wild environment) the same pattern did not copy. It could be a coincidence the sample that grown in Agra-polybag may contain specific toxic trace element used for strengthening and stabilizing poly bags.

Ingestion of these rhizomes as a medicinal herb is considered safe as along as the period of ingestion is kept short and with the quantified amount. Water infusion further reduced the risk of metal toxic poisoning possibly due to low extraction efficiency.

\section{Acknowledgments}

The authors gratefully acknowledge the financial support provided by the University of Malaya. The authors would like to express their deepest gratitude to Dr. Mohd Shuhaimi Hamzah and Mr. Md Shuhaimi Elias from Malaysian Institute of Nuclear Technology (MINT) for rendering the INAA and ICP-MS services and also for running the samples.

\section{Conflicts of interest}

Author declares there are no conflicts of interest.

\section{Funding}

None.

\section{References}

1. Tapsell LC, Hemphill I, Cobiac L, et al. Health benefits of herbs and spices: the past, the present, the future. Med J Australia. 2016;185(4 Suppl):S4-S24.

2. Eng-Chong, T, Yean-Kee L, Chin-Fei C, et al. Boesenbergia rotunda: From Ethnomedicine to Drug Discovery. Evid Based Complement Alternat Med. 2012;25.

3. Sivasothy Y, Chong WK, Hamid A, et al. Essential oils of Zingiber officinale var. rubrum Theilade and their antibacterial activities. Food Chem. 2011;124(2011):514-517.

4. Sontakke S, Thawani V, Naik MS. Ginger as an antiemetic in nausea and vomiting induced by chemotherapy: a randomized, cross-over, double blind study. Indian J Pharmaco. 2003;35:2-36.

5. Khalili H, Soltani R, Negahban S, et al. Reliability of Disk Diffusion Test Results for the Antimicrobial Susceptibility Testing of Nosocomial Gram-positive Microorganisms: Is E-test Method Better? Iran J Pharm Res. 2012;11(2):559-563.

6. Ismail $\mathrm{M}$, Bagalkotkar $\mathrm{G}$, Iqbal $\mathrm{S}$, et al. Anticancer Properties and Phenolic Contents of Sequentially Prepared Extracts from Different Parts of Selected Medicinal Plants Indigenous to Malaysia. Molecules. 2012;17(5):5745-5756. 
7. NIST. Trace Elements in Coal, (Bituminous). USA: National Institute of Standards and Technology (NIST); 1978.

8. Hombach M, Zbinden R, Böttger EC. Standardisation of disk diffusion results for antibiotic susceptibility testing using the sirscan automated zone reader. BMC Microbiology. 2013;13:225.

9. Manoharan A, Pai R, Shankar V, et al. Comparison of disc diffusion \& E test methods with agar dilution for antimicrobial susceptibility testing of Haemophilus influenzae. Indian J Med Res. 2003;117:81-87.
10. Bagalkotkar G. Isolation and Characterisation of Compounds from 'Naga Buana' (Phyllanthus Pulcher) and 'Similit Matinggi' (Casearia Capitellata) and their Cytotoxic Effects on Cancer Cell Lines, Master Thesis, Faculty of Medicine and Health Science. Malaysia: Universiti Putra Malaysia, serdang; 2007. pp 240.

11. Lalitha MK. Manual on antimicrobial susceptibility testing. India: Department of Microbiology, Christian Medical College; 2005. 